\title{
Investigation of Mercury Toxicity in Haematological Parameters to Fresh Water Fish "Cyprinus carpio"
}

\author{
Dr. Y. Thangam ${ }^{1}$, Dr. S. Umavathi ${ }^{2}$, V. B. Vysakh \\ ${ }^{1,2,3}$ PG and Research Department of Zoology, J.K.K. Nataraja College of Arts and Science, Komarapalayam, \\ Namakkal Dt, Tamilnadu, India
}

\begin{abstract}
This study represents the changes in the toxicant inorganic mercury. Inorganic mercury, have been reported to develop a disorder called acrodynia or "pink disease". Symptoms includes leg cramps, irritability, redness and peeling of the skin of hands, nose, and soles of the feet. Itching, fever, sweating, salivating, rashes (including "baboon syndrome" rashes in the buttocks, anal and genital regions), sleeplessness and/or weakness. Additional reports indicate the effects of inorganic mercury in children and adults include kidney damage and digestive tract problems including diarrhea, nausea, and ulcers. Table 1. Represent the data on changes in the hemoglobin content of the fish Cyprinus carpio exposed to sublethal concentration of mercury for 35 days. The hemoglobin content in the mercury exposed fish were found to be decreased when compared to the control showing a percent decrease of $-40.22,-40.00,-37.58$, $-31.00,-40.51$ at the end of 7,14,21,28,35 days. Table 2. Reveal the changes in red blood cell count of the blood of fish Cyprinus carpio exposed to sublethal concentration of mercury exposed fish for 35 days. The RBC count was decreased throughout the study period when compared to the control group showing a minimum percent decrease of -4.63 at the end of $7^{\text {th }}$ day and a maximum percent decrease of -16.66 at the end of $35^{\text {th }}$ day. Decrease in $R B C$ count in mercury exposed for $7^{\text {th }}, 14^{\text {th }}, 21^{\text {st }}$, $28^{\text {th }}$, and $35^{\text {th }}$ days, the percent observed was -4.63, -14.77, -11.17, -4.66, -16.66. Changes in the leucocytes count of fish Cyprinus carpio exposed to sublethal concentration of mercury for 35 days were presented in Table 3. During the above exposure period WBC count were decreased at $7^{\text {th }}$, $14^{\text {th }}$, days showing a percent decrease of $-3.28,-2.87$ and at the end of $21^{\text {st }}, 28^{\text {th }}$ and $35^{\text {th }}$ days WBC count increased showing a percent increase of $4.56,10.00,8.63$ respectively.
\end{abstract}

Keywords: Mercury chloride, Hemoglobin, erythrocytes, Leucocytes, Fish Cyprinus carpio

\section{Introduction}

Pollution is the introduction of contaminants into the natural environment that causes adverse change. Mercury is usually discharged into environment through the effluents from thermal power stations, paper and pulp industries, electronic wastes, batteries, electroplating, metal industries, fossil fuel combustion. It is also used in the manufacture of paints and dental amalgams [1]. Mercury chloride is a white powder soluble in water. Mercury chloride is the chemical compound of mercury and chloride with the formula $\mathrm{HgCl}_{2}$. Anthropogenic chemicals, salts, metals, in the environment are a major problem to aquatic organisms, human and wildlife. Many of these chemicals, salts used in industry and agriculture have a final destiny in the aquatic environment. Some of these chemical and salts are known to interfere with hematological parameters, which may disturb the growth function in fish [2]. Mercury (Hg) is considered as one of the most toxic metals due to carcinogenic characteristics. Fish exposed to different $\mathrm{Hg}$ concentrations in laboratory experiments have showed several affects, such as hormonal and reproduction alterations during the larval stage, alterations on hematological parameters [3]. Fish concentrate mercury in their bodies, often in the form of methyl mercury, a highly toxic organic compound of mercury. Mercury is a neuro toxicant, and may affect many areas of the brain. Neuro toxic symptoms of mercury exposure include poor performance on neurobehavioral tests of attention, fine motor function, language, visual-spatial abilities and verbal memory. The effects were found in field studies such as hematological, decrease of enzymatic activities (acetylcholinesterase) and Genotoxic effects [4].
Mercury exposure affect the mechanism of red blood cell turnover, inducing an anemic state [5]. Hematological parameters such as red blood cells counting, hemoglobin concentration, and leukocytes counts were observed.

Fishes are considered as one of the important food sources for human beings because their flesh contains a high percentage of proteins, calcium and phosphorus. Investigation regarding the health status of a fish can be assessed by hematological parameters. Hematology provides an index of physiological status of fish and the blood puncture of fish is an effective tool for detection of alterations in functional state of organism. Heavy metals have been reported to exert a wide range of metabolic, physiological, ecological and behavioral effects on fish. Hematological abnormalities have also been studied in various toxicant in determining the sub lethal concentration of pollutants such as heavy metal exposed fish: Chana punctatus to cadmium [6], Tilapia mossambica [7], Oreochromis aureus [8], Ctenopharyn godonidella [9], Aphanius dispar [10]. Cyprinus carpio to carbofuran [11]. In Tench impaired hematology of exposure to mercury treatments can be reflected in its behavior, with the assumption that in open water, impairments in physiological systems of fish on exposure to heavy metals pollution can be known from its behavioral activities, changes such as disturbances in metabolic pathways and ionic imbalance in blood serum [12]. The exposure of Channa punctatus to sub lethal concentrations of mercury led to anemia, as indicated by the significant decrease in $\mathrm{Hb}$, TEC, and TLC values leading to anemia. The anemia might have led to a fall in the red blood cell count, hemoglobin concentration and white blood count volume. The anemic condition in fish results 


\section{International Journal of Science and Research (IJSR) \\ ISSN (Online): 2319-7064 \\ Index Copernicus Value (2013): 6.14 | Impact Factor (2014): 5.611}

from an unusually low number of red blood cells or too little hemoglobin in the red blood cell [6] changes in the hematological profile of the fish exposed to mercury have been observed in Hoplias malabaricus [13], Mercury has the ability to be absorbed by the digestive tract and enter the blood stream.

In all hematological impairments observed in the present study, four physiological systems of fish such as (i) faulty gaseous exchange at gills, (ii) stress mediated hormonal imbalance, (iii) impaired osmoregulation and (iv) disturbed metabolism were found possibly involved and responsible for hematological changes. Hypoxia triggers erythropoiesis to compensate oxygen deficiency in the body, resulting in decreased number of erythrocytes and relevant indices. In the present investigation exposure of mercury to fresh water fish Cirrhinus mrigala were induced and changes were noted in the hematological parameters. The hemoglobin content, red blood cell count and white blood cell count were found decreased through the study period.

\section{Materials and Methods}

\subsection{Haematological Studies}

To assess the hematological profile of the control and treated fish, Hemoglobin, RBC and WBC counts were measured in the whole blood of Cyprinus carpio.

\subsection{Estimation of Haemoglobin}

Hemoglobin content of the blood was estimated by Cyanmethemoglobin method [14] using Diagnostic Reagent kit supplied by Monozyme India Ltd.

\subsection{Erythrocyte Count}

Erythrocytes were counted by the method of [15] using haemocytometer.

\subsection{Leucocyte Count}

Leucocytes were counted by the method of [15] using haemocytometer.

\section{Results}

Table 1. Represent the data on changes in the hemoglobin content of the fish Cyprinus carpio exposed to sublethal concentration of mercury for 35 days. The hemoglobin content in the mercury exposed fish was found to be decreased when compared to the control showing a percent decrease of $-40.22,-40.00,-37.58,-31.00,-40.51$ at the end of $7,14,21,28,35$ days. Table 2 . Reveal the changes in red blood cell count of fish Cyprinus carpio exposed to sublethal concentration of mercury exposed fish for 35 days. The RBC count was decreased throughout the study period when compared to the control showing a minimum percent decrease of -4.63 at the end of $7^{\text {th }}$ day and a maximum percent decrease of -16.66 at the end of $35^{\text {th }}$ day. Decrease in RBC count in mercury exposed for $7^{\text {th }}, 14^{\text {th }}, 21^{\text {st }}, 28^{\text {th }}$, and $35^{\text {th }}$ days, the percent observed was $-4.63,-14.77,-11.17$, 4.66, -16.66. Changes in the leucocytes count of fish Cyprinus carpio exposed to sublethal concentration of mercury for 35 days were presented in Table 3. During above exposure period WBC count was decreased $7^{\text {th }}, 14^{\text {th }}$, day showing a percent decrease of $-3.28,-2.87$, and at the end of $21^{\text {st }}, 28^{\text {th }}$, and $35^{\text {th }}$, days WBC count increased showing a percent increase of 4.56, 10.00, 8.63, respectively.

Table 1: Changes in the hemoglobin content of Cyprinus carpio exposed to sublethal concentration of mercury for 35 days

\begin{tabular}{|c|c|c|c|c|c|}
\hline $\begin{array}{c}\text { S. } \\
\text { No }\end{array}$ & $\begin{array}{c}\text { Exposure } \\
\text { Period }\end{array}$ & Control & Experiment & $\begin{array}{c}\text { Change } \\
\%\end{array}$ & $\begin{array}{c}\text { Calculated t } \\
\text { value }\end{array}$ \\
\hline 1 & 7 & $11.41 \pm 0.51$ & $6.82 \pm 0.74$ & -40.22 & -0.537 \\
\hline 2 & 14 & $10.00 \pm 0.71$ & $6.00 \pm 0.71$ & -40.00 & -0.728 \\
\hline 3 & 21 & $9.34 \pm 0.53$ & $5.83 \pm 0.60$ & -37.58 & -0.816 \\
\hline 4 & 28 & $9.00 \pm 0.71$ & $5.49 \pm 0.49$ & -39.00 & -0.750 \\
\hline 5 & 35 & $8.91 \pm 0.87$ & $5.30 \pm 0.54$ & -40.51 & -0.701 \\
\hline
\end{tabular}

Values are mean \pm S.E. of five individual observations.

(+) Denotes percent increase over control.

(-) Denotes percent decrease over control.

Table 2: Changes in the erythrocyte (RBC) count of Cyprinus carpio exposed to sublethal concentration of mercury for 35 days

\begin{tabular}{|c|c|c|c|c|c|}
\hline $\begin{array}{c}\text { S. } \\
\text { No }\end{array}$ & $\begin{array}{c}\text { Exposure } \\
\text { Period }\end{array}$ & Control & Experiment & $\begin{array}{c}\text { Change } \\
\%\end{array}$ & $\begin{array}{c}\text { Calculated } \\
\text { t value }\end{array}$ \\
\hline 1 & 7 & $0.365 \pm 0.15$ & $0.350 \pm 0.18$ & -4.63 & -0.350 \\
\hline 2 & 14 & $0.352 \pm 0.18$ & $0.300 \pm 0.10$ & -14.77 & -0.997 \\
\hline 3 & 21 & $0.331 \pm 0.17$ & $0.294 \pm 0.12$ & -11.17 & -0.226 \\
\hline 4 & 28 & $0.300 \pm 0.16$ & $0.286 \pm 0.17$ & -4.66 & -0.227 \\
\hline 5 & 35 & $0.300 \pm 0.17$ & $0.250 \pm 0.11$ & -16.66 & -1.062 \\
\hline
\end{tabular}

Values are mean \pm S.E. of five individual observations. $(+)$ Denotes percent increase over control.

(-) Denotes percent decrease over control.

Table 3: Changes in the erythrocyte (WBC) count of Cyprinus carpio exposed to sublethal concentration of mercury for 35 days

\begin{tabular}{|c|c|c|c|c|c|}
\hline $\begin{array}{c}\text { S. } \\
\text { No }\end{array}$ & $\begin{array}{c}\text { Exposure } \\
\text { Period }\end{array}$ & Control & Experiment & $\begin{array}{c}\text { Change } \\
\%\end{array}$ & $\begin{array}{c}\text { Calculated } \\
\text { t value }\end{array}$ \\
\hline 1 & 7 & $52.64 \pm 0.48$ & $50.91 \pm 0.58$ & -3.28 & -0.3508 \\
\hline 2 & 14 & $50.01 \pm 0.71$ & $48.60 \pm 0.51$ & -2.87 & -0.99 \\
\hline 3 & 21 & $43.34 \pm 0.79$ & $45.32 \pm 0.53$ & +4.56 & -0.226 \\
\hline 4 & 28 & $40.10 \pm 0.71$ & $44.11 \pm 0.71$ & -10.00 & -0.226 \\
\hline 5 & 35 & $36.83 \pm 0.60$ & $40.01 \pm 0.71$ & +8.63 & -1.062 \\
\hline
\end{tabular}

Values are mean \pm S.E. of five individual observations.

$(+)$ Denotes percent increase over control.

(-) Denotes percent decrease over control.

\section{Discussion}

Among heavy metals, mercury ( $\mathrm{Hg}$ ) is the most abundant, and is bio-accumulated by aquatic organisms and biomagnified through the food chain. Mercury causes strong toxicological effects on the cell membrane and many aspects of its toxic action have been attributed to its ability to cross the cell membrane and to disrupt cellular ion transport processes. Hematological parameters have been included, as they are measurable in blood and circulating levels of hormones can be altered by exposure to xenobiotic chemicals. Pollution of the environment is a serious and growing problem. Increasing number and amount of industrial, agricultural and commercial chemicals discharged 


\section{International Journal of Science and Research (IJSR) \\ ISSN (Online): 2319-7064 \\ Index Copernicus Value (2013): 6.14 | Impact Factor (2014): 5.611}

into the aquatic environment having led to various deleterious effects on the mercury [16]. The aim of this study was to determine the toxicity of mercury chloride exposed to fish Cyprinus carpio was chosen as an experimental animal on the basis of hematological parameters of important criteria. Heavy metals particularly mercury (Hg), are especially of a deep concern due to their high toxicity. Toxicity of mercury in fish depends on the sources of pollution, growth, rate of organism, sex, size and diversity of species. Mercury primarily targets the gills in fish leading to their death due to its high rate of accumulation, hypoxia and asphyxiation [17]. Mercury occurs naturally as a mineral and is widely distributed throughout the environment as a result of natural and human activities. Changes in erythrocyte shape were observed by [13] In Hoplias malabaricus fed lead containing feed. According to [18] lead was toxic to the newly developing erythrocytes of Carassius auratus, and also showed a genotoxic effect. Romero Reported an increased rate of apoptosis of mallard (Anasplatyrhynchos) erythrocytes incubated in vitro with $\mathrm{Pb}$ solutions. The obtained results showed that erythrocyte morphology was more sensitive to lead intoxication than basic red blood parameters, and that the erythrocyte nucleus was the main target of $\mathrm{Pb}$ action. And hematological changes, such as decrease in leucocytes in Channa punctatus on exposure to thermal stress to heavy metals, similarly the impairments in hematological parameters, such as drop and/or elevation in HCT, Hb, RBC, WBC in different fish species on heavy metals exposure have been reported and attributed to hemodilution, hemoconcentration, hemolysis and hemorraging, damage to hematopoietic tissues, accelerated erythroclasia, increased mechanical fragility, impaired osmoregulation, enzyme dysfunction, faulty gaseous exchange at gills leading to hypoxia and stress mediated hormonal imbalance [19].

The reduction in the red blood cell count due to the exposure of pesticides on the erythropoietic tissues as a result of the viability of the cells might be affected. In consistence with data, researchers have shown a reduction in these parameters in fish exposed to various toxic environmental exposure of fish to sub lethal concentrations of deltamethrin (0.075 mgl1 and $0.15 \mathrm{mgl}-1$ ) for 15, 30, 45 days caused significant alterations in hematological parameters of freshwater fish Channa punctatus.. The alterations observed in hematological parameters such as TEC, Hb, TLC value was significantly higher after 15 days of exposure, and decreased after 30 and 45 days of exposure in both concentrations. The hematological characteristics of various cultivated fish species have been studied to characterize their hematological profile [20]. [21], reported that the observation of hematological parameters allows the most rapid detection of changes in fish. According to [22], the study of the hematological picture is frequently utilized for the detection of physico pathological changes in different stress conditions such as exposure to heavy metals. A decrease in the erythrocyte count indicates the worsening of an organism state and it is developing anemia. Similar findings were observed in Puntius conchonius after mercury toxic exposure of 2 to3 week's duration by [23]. The decreases in hemoglobin concentration signifies that the fishes ability to provide sufficient oxygen to the tissues is restricted considerably and this would result in decrease of physical activity. [24] reported that the significant decrease in the hemoglobin concentrations may also be due to either an increase in the rate at which the hemoglobin is destroyed or to a decrease in the rate of hemoglobin synthesis. Decreases in the various parameters of blood were observed due to the treatment of $O$. mossambicus to different sublethal doses of phosalone for longer durations. The total numbers of RBCs and WBCs, the hemoglobin content value registered significant decreases $(\mathrm{P}<0.001)$. Such a decline in blood cells and hemoglobin content indicates the haemotoxicity of phosalone to fish. Lower hemoglobin level might decrease the ability of the fish to enhance its activity in order to meet occasional demands like seeking food and escape. The decrease in total erythrocyte count and hemoglobin concentration are often accompanied by decrease in haematocrit. This demonstrates the physiological dysfunction of the hemopoietic system. The reduction in RBC count may be due to the destruction of red blood cells and reduction in $\mathrm{Hb}$ content in each cell. Hemoglobin increased in Oreochromis hybrid [25], due to mercury exposure. [13] reported that physiological stress indicates changes in some hematological blood parameters that could be useful to evaluate the effects of contaminants in fish, but the application of these findings to preparation of environmental diagnoses wouldl need a more detailed investigation.

Significant decrease in the various parameters of blood were observed in Cyprinus carpio var. communis due to the treatment of different doses of mercury for short durations. The total number of RBC'S and WBC'S, the hemoglobin content value registered significantly decreased. This is an indication of severe anemia. The decline in blood cells and hemoglobin content was found to be depending on concentration and time dependent indicating the haemotoxicity of mercury to fish. The low levels of hemoglobin indicating anaemic conditions in fish may be due to stress caused hemolysis [26] and inhibition of aerobic glycolysis curtailing denova synthesis of hemoglobin. [27] also observed a quick decrease in hemoglobin content in response to Paraquat toxicity in Cyprinus carpio. The lower hemoglobin levels of treated fish in the present study might also be due to disruption of the iron synthesizing machinery. [26] observed reductions in hemoglobin content and red blood cell count of the fish Anabas scandens treated with mercury. Decrease in hemoglobin, Red blood cell (RBC) count was observed in fish Tinca tinca exposed to mercuric chloride and lead [19]. Decline in hemoglobin was observed in Channa Punctatus exposed to mercury [28] According to [29], about half of the mercury in blood is associated with red blood cells and the remaining half forms a complex with serum albumin by combination with sulfhydryl groups. The disturbed hemoglobin synthesis due to an effect of lead on amino levulinate dehydratase (ALA-D) may result in anemia [30]. Similar findings were observed in the O. mossambicus treated with mercury showed reduction in the Hb, TLC content and HCT level. High concentrations of heavy metals or long-term exposure of fish to their sublethal concentrations usually decrease the above-mentioned indices. Similar results with significant reduction of RBC and $\mathrm{Hb} \%$ content in fishes exposed to different heavy metals have been reported previously [31]. [6] found a significant decreased in total erythrocyte count, hemoglobin content, 


\section{International Journal of Science and Research (IJSR) \\ ISSN (Online): 2319-7064 \\ Index Copernicus Value (2013): 6.14 | Impact Factor (2014): 5.611}

leukocyte count concentration in air breathing fish. The decrease levels of hemoglobin may be due to anemic effect or increased destruction of hemoglobin or a decrease in the rate of hemoglobin synthesis. It have been be noted that this mixture of heavy metals had no effect on the count of white blood cells, while lower concentrations of lymphocytes were determined in the blood of perch dwelling in natural water bodies polluted with mixtures of heavy metals. This concurs with studies which proposed that toxicants are most times, organ specific in reaction.

The hematological characteristics of various cultivated fish species have been studied to characterize their hematological profile [20]. [21] reported that the observation of hematological parameters allows the most rapid detection of changes in fish. According to [22] the study of the hematological picture is frequently utilized for the detection of physio pathological changes in different stress conditions such as exposure to heavy metals. A decrease in the erythrocyte count or haematocrit indicates the worsening of an organism state and it is developing anemia. Similar findings were observed in Puntius conchonius after mercury toxic exposure of 2 to 3 week's duration. The decreases in hemoglobin concentration signifies that the fish's ability to provide sufficient oxygen to the tissues is restricted considerably and this will result in decrease of physical activity. [24] reported that the significant decrease in the hemoglobin concentrations may also be due to either an increase in the rate at which the hemoglobin is destroyed or to a decrease in the rate of hemoglobin synthesis. Increase of the leukocytes number and neutrophils counting in fish exposed to Hg were observed [14], related to tissue damages such as necrosis in different organs. Hg exposure could also affect the mechanism of blood cell turnover, inducing an anemic state [34]. In the present investigation significant decrease in the various parameters of blood were observed in Cyprinus carpio. var. communis due to the treatment of different doses of mercury for 35 days durations. The total number of RBC'S and WBC'S, the hemoglobin content value registered significantly decreased. This is an indication of severe anemia. The decline in blood cells and hemoglobin content was found to be depending on concentration and time dependent indicating the haemotoxicity of mercury to fish. The low levels of hemoglobin indicating anemic conditions in fish may be due to stress caused hemolysis. The significant decrease of hemoglobin concentration signifies that the fishes ability to provide sufficient oxygen to the tissues is restricted considerably and this results in decrease of physical activity. Significant reduction in RBC count may be due to the destruction of red blood cells and reduction in $\mathrm{Hb}$ content in each cell cause hypoxic conditions and paralysis of muscles of respiratory system in the body of fish. Hypoxia triggers erythropoiesis to compensate oxygen deficiency in the body, resulting in decreased number of erythrocytes and relevant indices. Significant decrease in WBC may be due to hemolysis and hemorrhaging, damage to hematopoietic tissues, enzyme dysfunction, faulty gaseous exchange leading to hypoxia and stress mediated hormonal imbalance. Increase in WBC might leads to tissue damage and causes necrosis in different organs.

\section{References}

[1] M. Moseley, M. H. Chen, S. K. Chang, S. W. Huang, "Total and organic mercury concentrations in the white muscles of swordfish (Xiphias gladius ) from the Indian and Atlantic oceans", Journal of Aquatic toxicology, 124, pp 62-68, 2006.

[2] A. M. Coimbra, E. M. A. Reis-Henriques, "Effects on gonads and circulating thyroid hormones during adulthood. Journal of Bulletin Environmental Toxicol, 79, pp 488-493. 2007.

[3] M. H. G, Berntssen, K. K. Hylland, A. K. Lundebye, R. Waagbo, "Maximum limits of organic and inorganic mercury in fish feed", Journal of Aquaculture 4, pp 593604. 2004.

[4] Z. C. Castilhos, N. R. P. Almosny, P. S.Souto, D. A. Pereira, L. C. Silva, C. Lindear, E. D. Bidone, "Bio assessment of ecological risk of Amazonian ichthyofauna to mercury", Journal of Bulletin Environmental Contamination Toxicology,72, pp 623635. 2003.

[5] P. S. S. Souto, "Recent advances in evaluation of health effects on mercury with special reference to methyl mercury", Journal of Environmental Toxicology, 25, pp 594-548. 2004.

[6] R. Karuppasamy, S. Subathra, S. Puvaneswari, "Hematological responses to exposure to sublethal concentration of cadmium in airbreathing fish", 45, pp 87-56, 2005.

[7] M. R. Menezes, S. Z. Quasim, "Effects of mercury accumulation on the electrophoretic patterns of the serum, hemoglobin and eye lens proteins of Tilapia mossambica", Journal of Toxicology, 34, pp 321-328, 1984.

[8] P. Allen, "Effects of acute exposure to cadmium (II) chloride and lead (II) chloride on the haematological profile of Oreochromisaureu", Journal of Comparative Physiology, 105 C, 213. 1994.

[9] A. R. Shakoori, M. J. Iqbal, A. L. Mughal, S. S. Ali, "Biochemical changes induced by inorganic mercury on the blood, liver and muscles of freshwater Chinese grass carp, Ctenopharyng odonidella", Journal of Ecotoxicology. 36, pp 124-136, 1994.

[10]A. M. Hilmy, M. B. Shabana, M. M.Said, “ Hematological responses to mercury toxicity in the marine teleost, Aphanius dispar (RUPP)", Journal of Comparitive. Biochemistry, pp 865-876, 1980.

[11] S. Chandra, R. N.Ram, I. J. Singh, "Toxic effects of carbofuran on certain hematological parameters in yearlings of Cyprinus carpio", Journal of Aquaculture, pp 3878-3884. 2001.

[12] S. L. Shah, "Behavioural abnormalities of Cyprinion watsonion exposure to mercury and zinc", Turkish Journal of Zoology, 26, pp 137-140, 2002.

[13] C. A. Oliveira-Ribeiro, F. F. Neto, M. Mela, P. H. Silva, M. A. F. Randi, I. S. Rabitto, J. R. M. Alves Costa, E. Pelletier, "Hematological findings in neotropical fish Hoplias malabaricus exposed to subchronic and dietary doses of methyl mercury, inorganic lead, and tributytlin chloride", Journal of Chemico Toxicology, 31, pp 821827, 2006.

[14]D. L.Drabkin, "Spectrometric studies, XIV-The crystallographic and optimal properties of the 


\section{International Journal of Science and Research (IJSR) \\ ISSN (Online): 2319-7064}

Index Copernicus Value (2013): 6.14 | Impact Factor (2014): 5.611

hemoglobin of man in comparison with those of other species", Journal of Biological Chemistry, 164, pp 703723. 1946.

[15] V. Russia, S. K. Sood, Routine haematological tests. In: Medical Laboratory Technology, Mukerjee K. L. ed. Tata McGraw Hill Publishing Company Limited, 252258.

[16]G. Begum, "Carbofuran insecticide induced biochemical alternations in liver and muscle tissues of fish Clarias batrachus (Linn.) and recovery response", Journal of Aquatic Toxicology. 66(1), pp 83-91. 2004.

[17]C. A. De Oliveira Ribeiro, L. Berlger, C. Pelletier RouleauC, "Histopathological evidence of inorganic mercury and methyl mercury toxicity in the arctic charr Salverlinus alpines", Journal of Environmental Research, 90, pp 217-225. 2002.

[18] T. Cavas. In vivo genotoxicity of mercury chloride and lead acetate Micronucleus test on acridine orange stained fish cells. Food and Chemo Toxicology 46, pp 349-352. 2008.

[19] S. L. Shah, A. Altindag, "Alterations in the immunological parameters of tench (Tincatinca L.) after acute and chronic exposure to lethal and sublethal mercury treatments", Journal of Bulletin Environmental Contamination Toxicology, 73, pp 911-918, 2004.

[20] M. J. T. Ranzani-Paiva, C. M. Ishikawa, A. C. Eiras, V. R. Silveira, "Effects of an Experimental Challenge with Mycobacterium marinum on the Blood Parameters of Nile Tilapia, Oreochromis niloticus (Linnaeus, 1757)", Journal of Brazilirain. Archive. BioTechnology. 47(6), pp 945-953. 2004.

[21] O. A. Osho, A. A. Bakare, A. A. Adeogun, A. A. Sowunmi, " Ecotoxicological Assessment using Clarius gariepinus and Microbial Characterization of Leachate from Municipal Solid Landfill", International Journal of Environmental Research, 2(4), pp 391-400, 2008.

[22] G. Nussey, J. H. J. VanVuren, H. H. DuPreez, "Effects of mercury on hematology and osmoregulation of the Mozambique tilapia, Oreochromis mossambicus (Cichlidae)", Journal of Comparative Biochemistry Physiology. 111, pp 369-380. 1995.

[23] T. S. Gil, J. C. Pant, "Hematological and pathological effects of chromium toxicosis in the freshwater fish, Barbus comchoniu ham", Journal of Water, Air Soil Pollution", 35, pp 421-450.1987.

[24] P. M. Reddy, M. Bashanihideen, "Fenvalerate and cypermethrin induced changes in the hematological parameters of Cyprinus carpio", Acta Hydrochemistry. Hydrobiology. 17, pp101-107, 1989.

[25] T. C. Hrubec, J. L. Cardinale, S. A. Smith," Hematology and plasma chemistry reference intervals for cultured tilapia (Oreochromis hybrid)", Journal of Vetinary Clinical Pathology, 9(1) , pp 7-12, 2000.

[26] A. K. Panigrahi, B. N. Misra, "Toxicological effects of mercury on a fresh water fish Anabas scandens, CUV and VAL and their ecological implications", Journal of Environmental Pollution. 16, pp 31-39, 1987.

[27] B. Matkovics, H. O. Wiltas, "Paraquat as an agent affecting antioxidant enzymes of common carp erythrocytes", Journal of Comparative Biochemistry Physiology, 87c, pp 217-219, 1981.

[28]K. V. Sastry, K. Sharma, “ Mercury induced hematological and biochemical anomalies in ophiocephalus (Channa punctatus)", Journal of Toxicology,5, pp 245-249, 1980.

[29] T. W. Clarkson, J. Gatzy, C. Dalton, "Studies of the equilibrations of mercury vapour with blood" University of Rochester, New York. AEP Report No. 582.1961.

[30] M. A. Santos, A. Hall, "Influence of inorganic lead on the biochemical blood composition of the eel, Anguilla anguilla L",Journal of Ecotoxicology Environment Safety, 20, pp 7-9, 1990.

[31]K. A. Goel, M. L. Sharma, "Some hematological characteristics of Clarias batrachus under metallic stress of arsenic". Journal of Comparative Physiology Ecology, 12, pp 63-66, 1987.

[32] L. C. C. P. Silva," Blood dyspraxia in a Teleost", Colisa fasciatus associated with cadmium poisoning. Journal of Aquaculture, 24, pp 48-51, 2004. 